\title{
Theoretical Analysis on the Economic Performance of Micro Gas Turbine-Trigeneration System with Different Operation Strategies for Residential Building in a Tropical Region
}

\author{
Firdaus Basrawi ${ }^{1, a}$, MRR Chand ${ }^{1}, \mathrm{KH} \mathrm{Koo}^{1}$ and Thamir K Ibrahim ${ }^{1}$ \\ ${ }^{1}$ Energy Sustainability Focus Group, Faculty of Mechanical Engineering, UMP, Pekan, Pahang, Malaysia
}

\begin{abstract}
This study investigates how operation strategies of micro gas turbine trigeneration system (MGTTGS) affect its economic performance. MGT-TGS was required to sustain power, heating and cooling load of 148 residential terrace houses located in Kuala Lumpur. Based on the load requirement, there were two sizes of MGTs adopted in the research scope, a $30 \mathrm{~kW}$ and $60 \mathrm{~kW}$ respectively. Four typical operation strategies; powermatch, heat-match, mix-match, and base-load were investigated. Life cycle cost analyses with Net Present Value as the indicator were carried out. It was found that MGT-TGS can only generate positive NPV within 25 years of life time under unsubsidized electricity price. In addition, only mix-match and power-match operation strategies offered positive NPV. Under the scheme of the latter operation strategies, the MGT achieved power generation efficiency ranging from $27 \%$ to $28 \%$ respectively due to higher partial load ratio. Furthermore, these operation strategies generated excess electricity that consequently increased the profit from electricity saving. Economically, there were less capital cost, operation and maintenances (O\&M) cost and replacement cost on operating the system under the mixed match scheme and power match scheme. However Net Present Value analysis indicated that the mixed match strategies offer better economic performances than power match strategies and other operation strategies for the MGT-TGS.
\end{abstract}

\section{Introduction}

Cogeneration System (CGS) and Trigeneration System (TGS) are several alternatives available for sustainable development in power generation sector. Since they are operated close to the demand-side, they have advantage in term of utilizing exhaust heat for heating and cooling purposes. Reciprocating engines and micro gas turbines (MGT) are commercially available prime movers for C/TGS applications. MGT have less power generation efficiency as compared to reciprocating engines, but they emit lower emissions especially CO and NOx. With the air bearing technology, regular maintenance is also much easier because only air filter is need to be replaced. Moreover, waste heat can be utilized much easier because heat only need to be recovered at the exhaust gas stage. The quality of heat is also good, with temperature exceeding $200^{\circ} \mathrm{C}$. Thus, MGT is another option if maintenance factors, waste heat utilization, and environment aspects are fairly considered.

However, the claimed efficiency of MGT is commonly valid for rated operation. The efficiency drastically decreases during partial load operation, and

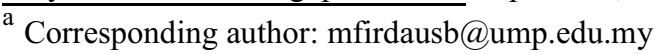

therefore it is important to analyse their performance during the system design stage. Partial load operation cannot be avoided because operation of a C/TGS depends on the operation strategy employed. Basic operation modes for C/TGS are power-match mode, heat-match mode, mixed-match mode, and base-load. Proper selection of operation strategy will determine C/TGS performance. Thus, investigation on how operation strategies effect the performance of MGT-TGS in a particular application is very important.

There are many recent studies on system design and analysis reported on the MGT-TGS. The performances of a MGT-C/TGS in sewage treatment plants were investigated in few literatures where MGT-TGS offer better efficiency than MGT-CGS [1-3]. Sugiartha et al [4] performed work on analysing the Fuel Saving Ratio (FESR), $\mathrm{CO}_{2}$ emission and payback period of MGT-TGS under two different operation strategies. The research concluded that the MGT-TGS offer high efficiency in full load operation mode. Moya et al [5] had studied on MGT-TGS reliability based on type of application where large residential building and medium sized hotel were considered. It was found that MGT-TGS were suitable for large residential building compared to medium size hotel because of the high payback period and lower 
efficiency on small scaled applications. There are studies on the method of sizing MGT, economic, environmental and efficiency performance in CGS and TGS for a 10 storey residential building located in Iran $[6,7]$. The double effect absorption chiller COP and MGT performances were investigated theoretically through manipulating the ambient temperature as well as fuel mass flow rate [8]. The studies concluded that ambient temperature plays an important role in operating MGT for power generation. As the ambient temperature in tropical regions are high, the performances of MGT-C/TGS was studied to determine the reliability of the system for application in tropical region [9]. However, in the studies, the MGT was simulated to satisfy the power demand only.

Based on the literature reviewed, there is no study reported on the effect of operation strategies on the economic performance of MGT-TGS in a tropical region. Thus, the objective of this study is to clarify how the operation strategy affects the economic performance of MGT-TGS. Four operation strategies were studied. MGT with power capacity output of $30 \mathrm{~kW}$ or $65 \mathrm{~kW}$ were used as the prime mover. Then, the capacity of all equipment for each operation strategy was determined by energy balance calculation. Finally, Net Present Value for 25 years life cycle of each operation strategy were compared.

\section{Methodology}

The weather data of Kuala Lumpur was used as the input for all related calculations. It was found that ambient temperature almost constant throughout the year with the difference of the ambient temperature of Malaysia is between $33^{\circ} \mathrm{C}$ and $24^{\circ} \mathrm{C}[10]$.

Energy demand of a group of 148 terrace houses need to be covered by the TGS. Each house has $6.5 \mathrm{~m}$ width and $19.8 \mathrm{~m}$ length with the total area of $129 \mathrm{~m}^{2}$. Energy load of the house was obtained by surveys that reported in. A particular length of hot and cold water pipeline and power requirement of water pumps were also needed in the calculation of heat losses and power for water pumping. Energy demand of a single house is shown in Table 1. It was found that power demand is usually higher during day time, whereas cooling demand is higher during night time.

This is because during day time, electric appliances such as television, cooker and iron were in frequent usage, on the other hand during night time, only cooling energy were required at most which lead to higher cooling demand. Most of the electric appliances were switch off during night time. Subsequently higher energy is required during night time compared to day time in residential application [11]. The amount of energy demand was multiplied to 148 as the total energy demand for all houses that need to be covered by MGT-TGS.

The maximum power demand of 148 terrace houses in a particular day was $63.64 \mathrm{~kW}$ as recorded at $7 \mathrm{a} . \mathrm{m}$ the minimum power demand recorded was $28.12 \mathrm{~kW}$ at 11 p.m and 12p.m respectively. Henceforth, a $65 \mathrm{~kW}$ MGT was adapted in the analysis for various operation strategies excluding base load operation strategies. In the case of base load operation, a 30kW MGT was adapted in the analysis. The MGT were sized accordingly to the power demand as over sizing will lead to regular partial operations which reduces the MGT efficiency.

Schematic diagram of MGT-TGS energy system is illustrated in Fig. 1, where MGT act a prime mover providing electric energy to the demand side. The exhaust heat of the MGT is recovered by a heat exchanger for water heating use, and the rest was supplied to the absorption chiller. The absorption chiller then converted heat to cover cooling demand of the houses. A boiler was also used as a back-up whenever heat from MGT was insufficient.

Table 1. Energy demand of the selected building[12]

\begin{tabular}{|c|c|c|c|}
\hline $\begin{array}{l}\text { Time } \\
\text { (h) }\end{array}$ & $\begin{array}{c}\text { COOLING } \\
(\mathrm{kW})\end{array}$ & $\begin{array}{c}\text { POWER } \\
(\mathrm{kW})\end{array}$ & $\begin{array}{c}\text { W. HEATING } \\
(\mathrm{kW})\end{array}$ \\
\hline 1 & 0.65 & 0.27 & 0.02 \\
\hline 2 & 0.57 & 0.3 & 0.01 \\
\hline 3 & 0.54 & 0.32 & 0.01 \\
\hline 4 & 0.49 & 0.33 & 0.01 \\
\hline 5 & 0.45 & 0.35 & 0.01 \\
\hline 6 & 0.2 & 0.42 & 0.01 \\
\hline 7 & 0.14 & 0.43 & 0.02 \\
\hline 8 & 0.05 & 0.36 & 0.13 \\
\hline 9 & 0.05 & 0.35 & 0.14 \\
\hline 10 & 0.05 & 0.32 & 0.17 \\
\hline 11 & 0.05 & 0.36 & 0.13 \\
\hline 12 & 0.06 & 0.37 & 0.11 \\
\hline 13 & 0.06 & 0.38 & 0.1 \\
\hline 14 & 0.09 & 0.37 & 0.1 \\
\hline 15 & 0.09 & 0.4 & 0.07 \\
\hline 16 & 0.09 & 0.41 & 0.07 \\
\hline 17 & 0.07 & 0.41 & 0.07 \\
\hline 18 & 0.08 & 0.4 & 0.08 \\
\hline 19 & 0.12 & 0.36 & 0.1 \\
\hline 20 & 0.24 & 0.3 & 0.13 \\
\hline 21 & 0.31 & 0.28 & 0.12 \\
\hline 22 & 0.6 & 0.2 & 0.1 \\
\hline 23 & 0.71 & 0.19 & 0.08 \\
\hline 24 & 0.7 & 0.19 & 0.08 \\
\hline
\end{tabular}

On the power management side, MGT produces power, and some of the power produced could be stored in a battery bank. However, there were inverter and converter for charging/discharging process. In addition, insufficient or surplus electricity could be bought or sold to the grid network.

Four operation strategies were examined in this study; (1) power-match, (2) heat-match, (3) mix-match, and (4) base-load. In power-match operation, MGT follows the power demand. Imbalance between the heat supply and demand is controlled by the heat storage, and boiler is used as a back-up. In heat-match operation, MGT follows the total heating and cooling load. Power 
demand is covered by MGT and imbalance between power supply and demand is controlled by the battery and grid network. In mix-match operation, MGT follows the higher load, either heat or power load. This resulting in full utilization of MGT capacity. As the power-match, imbalance between the heat supply and demand is controlled by the heat storage, and boiler is used as backup. In addition, surplus electricity is sold to the grid.

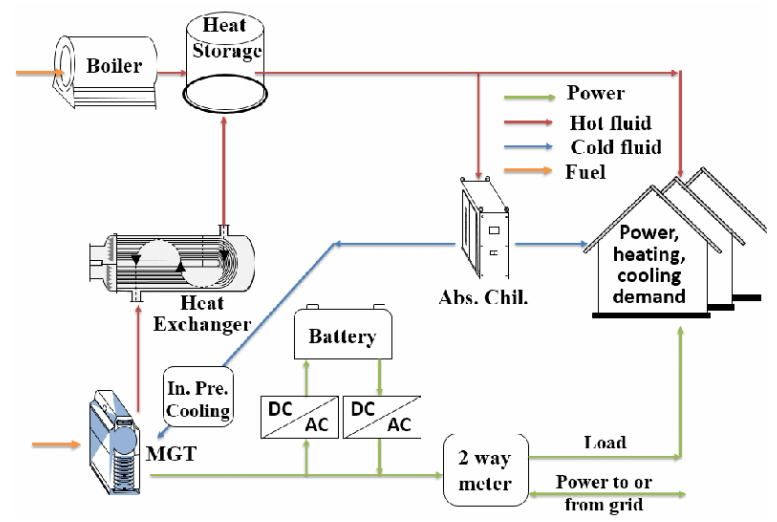

Figure 1. Configuration of the energy system

Power generation efficiency of MGT drastically decreases at partial load operation. Operation strategies stated above cannot avoid partial load operation. Thus, smaller MGT that run at base load is another good option. This ensures maximum efficiency of MGT. Imbalance and insufficient cooling and heating load can be covered by the heat storage and the boiler.

The MGT-TGS studied in the previous research in were adopted as the model. This MGT-TGS was a recuperated single shaft MGT, coupled with tube-shell exhaust heat recovery and single stage water-lithium bromide absorption chiller. Table 2 shows the basic specifications of the MGT, exhaust heat exchanger and absorption chiller.

Overall efficiency $\eta_{\text {ove }}$, power generation efficiency $\eta_{P e}$, and exhaust heat recovery efficiency $\eta_{Q e h r}$ for MGTs under partial load operation are shown in Fig. 2.

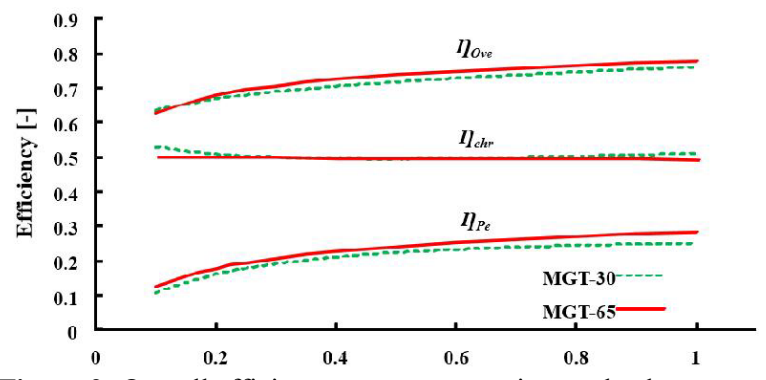

Figure 2: Overall efficiency, power generation, and exhaust heat recovery of MGT-30 and MGT-65 [9].

Calculation for cooling output and COP of the absorption chiller at different heat medium temperature can be simplified by the following calculations[12]:

$$
\begin{aligned}
& Q_{\text {cooling }}=2.2281 \cdot t_{h m}-125.34, \\
& C O P_{A B . C}=0.0019 \cdot t_{h m}+0.635,
\end{aligned}
$$

Table 2. Basic specifications of the MGT, Exhaust heat exchanger, Absorption chiller[12, 13].

\begin{tabular}{|l|c|c|}
\hline \multicolumn{3}{|c|}{ Micro Gas Turbine } \\
\hline Rated Power $(\mathrm{kW})$ & 30 & 60 \\
\hline Exhaust temperature $\left({ }^{\circ} \mathrm{C}\right)$ & 273 & 309 \\
\hline Exhaust mass flow rate $(\mathrm{kg} / \mathrm{s})$ & 0.31 & 0.49 \\
\hline Rated electrical power output $(\mathrm{kW})$ & 30 & 65 \\
\hline Fuel input $(\mathrm{kW})$ & 115 & 224 \\
\hline Electrical efficiency $(-)$ & 0.26 & 0.29 \\
\hline \multicolumn{3}{|c|}{ Exhaust Heat Exchanger } \\
\hline Effectiveness $(-)$ & 0.80 & 0.80 \\
\hline Cold water inlet temperature $\left({ }^{\circ} \mathrm{C}\right)$ & 80 & 80 \\
\hline Cold water mass flow rate $(\mathrm{kg} / \mathrm{s})$ & 1.22 & 1.81 \\
\hline Rated heat recover $(\mathrm{kW})$ & 56 & 105 \\
\hline Capacity ratio $(-)$ & 0.062 & 0.066 \\
\hline NTU(-) & 1.719 & 1.727 \\
\hline \multicolumn{3}{|c|}{ Absorption Chiller } \\
\hline Cooling outlet temperature $(-)$ & 7 & 7 \\
\hline Rated heat medium temperature $\left({ }^{\circ} \mathrm{C}\right)$ & 88 & 88 \\
\hline Standard cooling capacity(kW) & 103 & 103 \\
\hline $\begin{array}{l}\text { Standard heat medium input } \\
\text { capacity(kW) }\end{array}$ & 150 & 150 \\
\hline
\end{tabular}

Life cycle cost analysis was calculated to analyse economic performance. In this calculation, Net Present Value (NPV) was calculated in which all value of cash flows in the future are discounted to their present value. NPV for 25 years of the life cycle can be calculated by the following equation:

$$
N P V=P r_{P e}-\left(\begin{array}{l}
C_{e q}+C_{\text {ins }}+C_{O \& M} \\
+C_{r e p}-C_{\text {sal }}+C_{\text {fuel }}+C_{\text {grid }}
\end{array}\right),
$$

$C_{\text {grid }}$ is the electricity cost for buying or selling electricity to grid. It should be noted that buying had positive value and selling had negative value in the equation. Table 3 shows parameters used for the calculation.

Equipment cost can be calculated as the following equation:

$$
\begin{aligned}
C_{e q}= & C_{e q, M G T-C G S}+C_{e q, a b s . c .}+C_{e q, \text { boiler }} \\
& +C_{e q, \text { h.storage }}+C_{e q, \text { battery }}+C_{\text {eq,i.p.c. }}
\end{aligned}
$$

The installation cost including installation of building construction, equipment, and land acquisition was assumed to be $20 \%$ of the capital cost. Operation and maintenance $(\mathrm{O} \& \mathrm{M})$ costs $C_{O \& M}$ was calculated by the following equations:

$$
C_{O \& M}=C_{O \& M, M G T-C G S}+C_{O \& M, A B . C}+C_{O \& M, b a t t e r y},
$$


Table 3. Parameters used for the cost and pay back calculations[12].

\begin{tabular}{|c|c|c|}
\hline Exchange rate & \multicolumn{2}{|c|}{ 1US\$ = RM3.00 } \\
\hline \multicolumn{3}{|c|}{ Energy price } \\
\hline Natural gas & $\mathrm{US} \$ / \mathrm{m}^{3}$ & 0.197 \\
\hline Electricity & $\mathrm{US} \$ / \mathrm{kWh}$ & 0.115 \\
\hline \multicolumn{3}{|c|}{ Initial cost (Overnight) } \\
\hline MGT-CGS & $\mathrm{US} \$ / \mathrm{kW}$ & 1300 \\
\hline AB.C & $\mathrm{US} \$ / \mathrm{kW}$ & 300 \\
\hline $\mathrm{PV}$ & $\mathrm{US} \$ / \mathrm{kW}$ & 3210 \\
\hline Battery & US\$/kWh & 1500 \\
\hline Heat Storage & $\mathrm{US} \$ / \mathrm{m}^{3}$ & 5500 \\
\hline Boiler & $\mathrm{US} \$ / \mathrm{kW}$ & 90 \\
\hline Inlet precooling & US\$/kW & 20 \\
\hline \multicolumn{3}{|c|}{ Lifetime } \\
\hline MGT-CGS & year & 25 \\
\hline AB.C & year & 25 \\
\hline Battery & year & 15 \\
\hline Boiler & year & 15 \\
\hline \multicolumn{3}{|c|}{ Salvage and Market Value } \\
\hline Battery (depreciation rate) & $\% /$ year & 5.3 \\
\hline Boiler (depreciation rate) & $\% /$ year & 6.0 \\
\hline \multicolumn{3}{|c|}{$O \& M$ cost } \\
\hline MGT-CGS & $\mathrm{US} \$ / \mathrm{kWh}$ & 0.01 \\
\hline AB.C & $\mathrm{US} \$ / \mathrm{kWh}$ & 0.001 \\
\hline
\end{tabular}

Equipment cost can be calculated as the following equation:

$$
\begin{aligned}
C_{e q}= & C_{e q, M G T-C G S}+C_{e q, a b s . c .}+C_{e q, b o i l e r} \\
& +C_{e q, h . s t o r a g e}+C_{e q, b a t t e r y}+C_{e q, i . p . c .}
\end{aligned}
$$

The installation cost including installation of building construction, equipment, and land acquisition was assumed to be $20 \%$ of the capital cost. Operation and maintenance $(\mathrm{O} \& \mathrm{M})$ costs $C_{O \& M}$ was calculated by the following equations:

$$
C_{O \& M}=C_{O \& M, M G T-C G S}+C_{O \& M, A B . C}+C_{O \& M, b a t t e r y},
$$

General Present Value, $P V x$ of a uniform series of payment can be calculated by the following equation:

$$
P V_{x}=P V F_{A U P} \cdot A U P_{x}
$$

In the case of revenue by not buying electricity from grid, AUP is the amount of that revenue for a year. $P V F_{A U P}$ can be calculated through Eq. (9) where the interest rate was considered as $4.55 \%$.

$$
P V F_{A U P}=\frac{(1+i)^{n}-1}{i(1+i)^{n}}
$$

For equipment that has a lifetime of less than 25 years, replacement cost was also calculated. In addition, salvage values for equipment at the end of their lifetime, and market values for equipment at the end of their lifetime were also considered. Depreciation rate shown in Table 2 was used for that purpose. The replacement cost and salvage cost/value can be calculated by the following equations:

$$
\begin{gathered}
P V_{\text {rep }, x}=P V F_{S P @ S R} \cdot C_{\text {rep }} \\
P V_{\text {sal }, x}=P V F_{S P @ S R} \cdot C_{\text {sal }}
\end{gathered}
$$

Where $P V F_{S P @ S R}$ for present worth factor for a single payment or single return and it can be calculated as below:

$$
P V F_{S P @ S R}=\frac{1}{(1+i)^{n}}
$$

Finally, fuel cost and operation and maintenance cost can be calculated with the same method of revenue from electricity saving. Price of Natural gas is shown in the Table 3.

\section{Result and Discussion}

Results on the capacity of each component of operation strategy are shown in Table 4. As shown in the Table 4, since more excess power at night need to be utilized during day time, heat-match had the largest capacity of battery. It was also found that, base-load had the largest heat storage because less heat generation due to its smaller capacity of MGT.

Conditions of power demand and output in all operation strategies are shown in Fig. 3. Fig. 3a, Fig. 3b, Fig. 3c and Fig. 3d shows results for power-match, heatmatch, mix-match, and base-load, respectively. As shown in Fig. 3a, MGT operation load can drop down to $50 \%$ of partial load in power-match mode. As shown in Fig. 3b, since MGT followed the heat demand, its power generation condition also varied. In addition, MGT operation decreased down to $10 \%$ of partial load. With the support of battery, insufficient power during early morning can be covered by surplus power during night time. On top of that insufficient power was also supplied by the grid network.

For base-load operation strategy, MGT only supplied power at base load and the rest of load was covered by the grid. Thus, this maintained high partial load ratio. As shown Fig. 3c, for mix-match operation strategy, MGT supplied more than power demand during night time because it followed heat load at that time. However, surplus of electricity was sold to the grid, and further generate profit. This also maximize the partial load ratio for mix-match. 
Table 4. Component required for each case and their capacity.

\begin{tabular}{|c|c|c|}
\hline Operation Strategy & Component & $\begin{array}{c}\text { Capacity } \\
(\mathrm{kW} \text { or kWh })\end{array}$ \\
\hline \multirow{6}{*}{ Power match } & MGT & 65.0 \\
\hline & Battery & 0.0 \\
\hline & IPC & 7.4 \\
\hline & AHP & 105.0 \\
\hline & Heat Storage & 10.0 \\
\hline & Boiler & 0.0 \\
\hline \multirow{6}{*}{ Heat match } & MGT & 65.0 \\
\hline & Battery & 172.8 \\
\hline & IPC & 4.3 \\
\hline & AHP & 105.0 \\
\hline & Heat Storage & 0.0 \\
\hline & Boiler & 58.0 \\
\hline \multirow{6}{*}{ Mix match } & MGT & 65.0 \\
\hline & Battery & 0.0 \\
\hline & IPC & 7.4 \\
\hline & AHP & 105.0 \\
\hline & Heat Storage & 4.8 \\
\hline & Boiler & 0.0 \\
\hline \multirow{6}{*}{ Base load } & MGT & 30.0 \\
\hline & Battery & 0.0 \\
\hline & IPC & 5.0 \\
\hline & $\overline{\mathrm{AHP}}$ & 105.0 \\
\hline & Heat Storage & 14.3 \\
\hline & Boiler & 63.8 \\
\hline
\end{tabular}

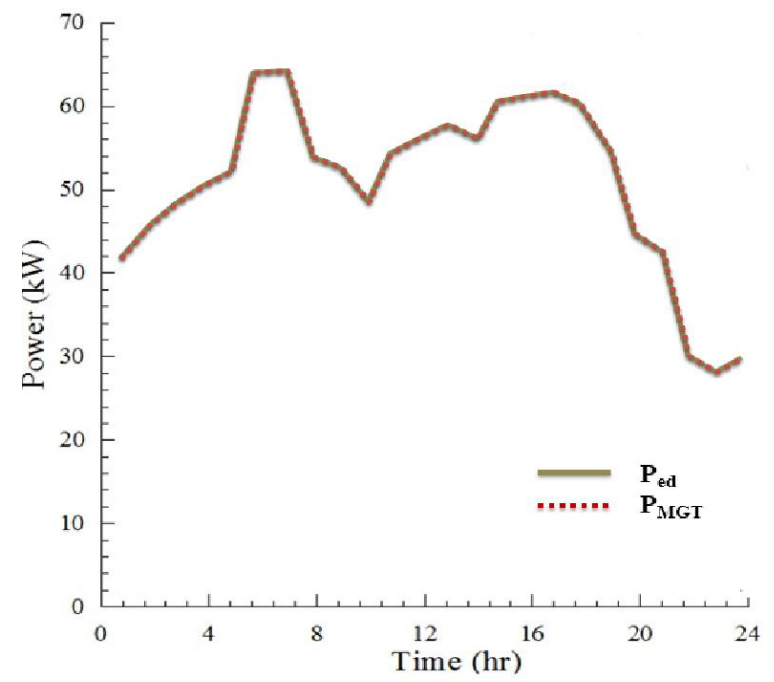

Figure 3a. Power demand and Output in Power Match Strategy

Detail on the partial load ratio are shown in Fig. 4. As shown in Fig. 4, heat-match had the lowest average load ratio, 0.50 . This partial load affected the efficiency of the MGT-TGS. As also shown in Fig. 4, heat-match had the lowest power generation efficiency.

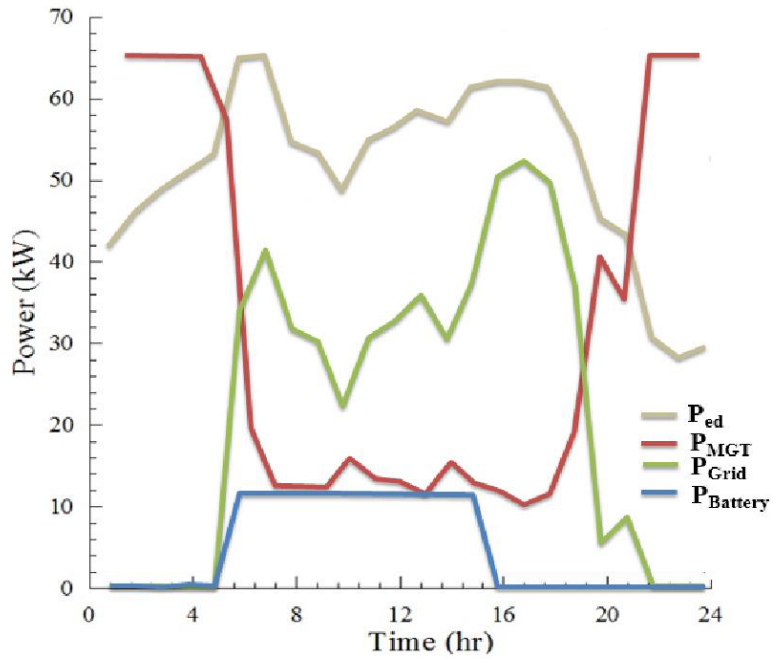

Figure 3b. Power demand and Output in Heat Match Strategy

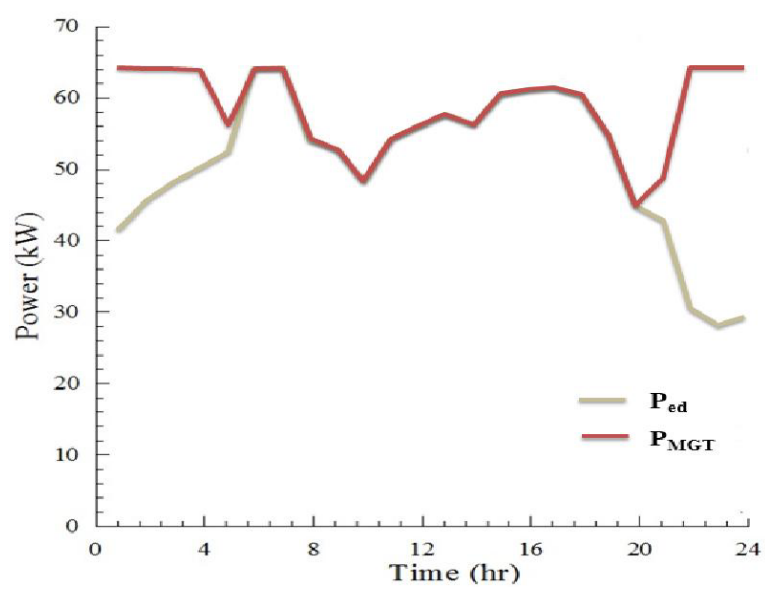

Figure 3c. Power demand and Output in Mixed Match Strategy

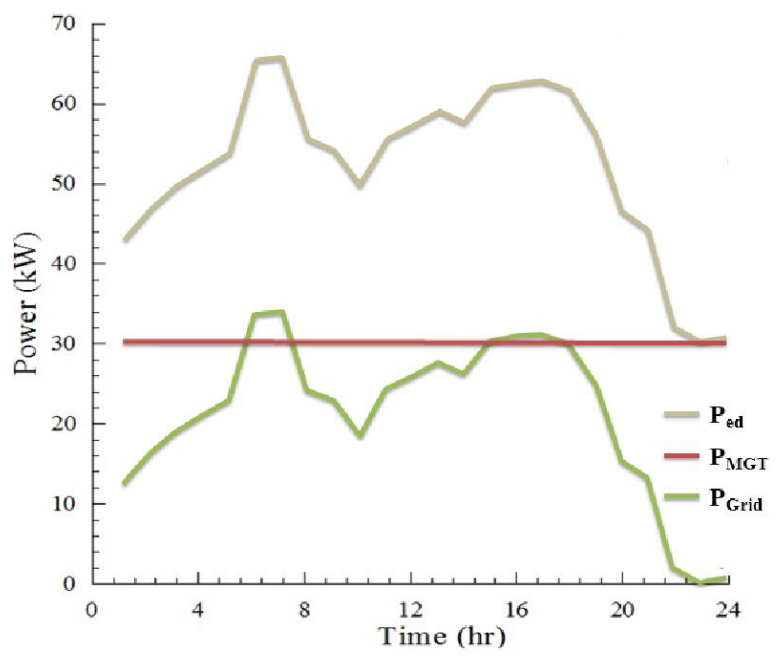

Figure 3d. Power demand and Output in Base Load Operation

Although base-load had the highest load ratio, the highest power generation efficiency is shown by mixmatch. This is because base-load used smaller capacity of 
MGT that had the limit of power generation efficiency of 0.26 . Thus, although mix-match had slightly lower partial load ratio, it had the highest efficiency because it used larger MGT that has power generation efficiency limit of 0.29 .

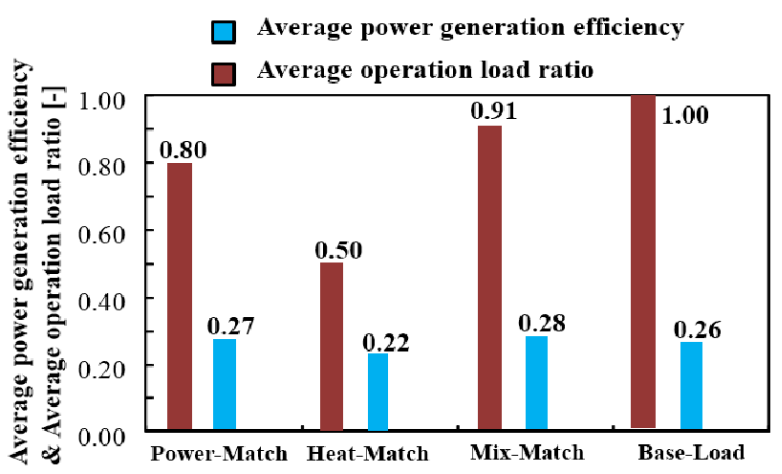

Fig. 4 Results on the power generation efficiency and load ratio

Results on the economic performance of the MGTTGS are shown in Fig. 5. Grey bar and white bar shows NPV when the electricity price are subsidized and unsubsidized, respectively. When the electricity price was highly subsidized, none of the MGT-TGS can generate positive NPV throughout the 25-year life cycle time. However, when the unsubsidized price of electricity was considered, power-match and mix-match had positive NPV. The main reason was mix-match and power-match generates more electricity than rest of operation strategies. This can futher seen from Fig. 6.

The breakdown of NPV for unsubsidized condition in Fig. 6 clearly shown that mix-match and power-match had higher revenue from electricity saving $P r_{P e}$. Thus, when unsubsidized electricity cost is considered revenue by not buying electricity from grid drastically increased for these operation strategies. Thus, mix-match and power-match operation strategies are better solutions from economic point of view.

Another factor was the power generation efficiency of the MGT as shown in Fig. 4. Higher power generation efficiency contribute to the less fuel cost. On top of that, mix-match and power-match also had less equipment, and therefore less equipment cost, O\&M cost, replacement cost was achieved.

However, when mix-match and power-match is compared, Mix-match had higher NPV. Thus, mix-match is the best operation strategy for this application when economic factor is considered.

\section{Conclusion}

Economic performance of Micro Gas TurbineTrigeneration System (MGT-TGS) that operated in different operation strategies were investigated.

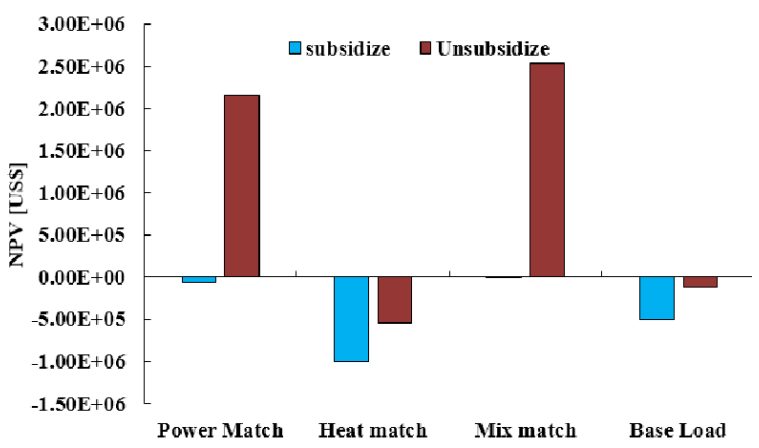

Figure 5. Results on the economic performance of the MGTTGS
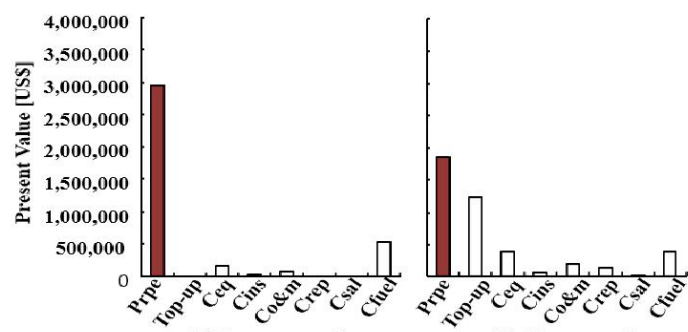

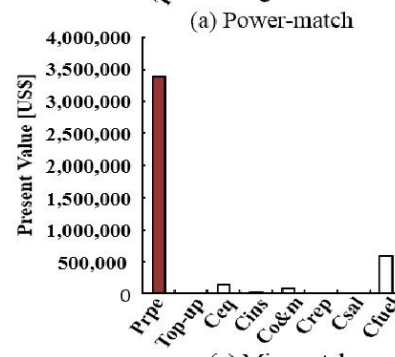

(c) Mix-matcl (b) Heat-match

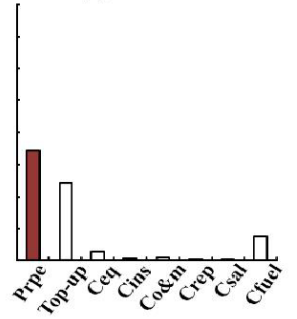

(d) Base-load
Figure 6. Breakdown of the NPV for all operation strategies

It was found that all operation strategies can only generate positive NPV at the end of 25 years life time when unsubsidized electricity price was considered

Mix-match and power-match operation strategies can generate positive NPV compared to other operation strategies. The main reason was mix-match and powermatch generates more electricity than the rest of operation strategies. Thus, when unsubsidized electricity cost is considered revenue by not buying electricity from grid drastically increased for these operation strategies. Other factors were higher power generation efficiency due to higher partial load ratio, and less equipment needed in those operation strategies that could reduce equipment cost, O\&M cost and replacement cost. When mix-match and power-match is compared, mix-match had higher NPV, and therefore mix-match is the best operation strategy for this application in terms of economic performance. 
However, further investigation in terms of emissions must also be studied in the future and comparison on the environmental performances of different power generation with the respective MGT-TGS should be performed.

\section{Acknowledgement}

The author would like to acknowledge the authority of Malaysia Ministry of Education and University Malaysia Pahang upon the funding provided for the research under grant RDU130133 or (FGRS/2/2013/TK06/UMP/02/1).

\section{Nomenclature}

$\begin{array}{lll}A & \left.: \text { Area[ } \mathrm{M}^{2}\right] \\ A U P & : \text { Annual Uniform Payment [Us\$] } \\ C & : \text { Cost [US\$] } \\ \text { Cap } & : \text { Capacity [Kw Or Kwh Or } \mathrm{M}^{3} \text { ] } \\ \mathrm{I} & : \text { Interest [-] } \\ \mathrm{n} & : \text { Life Time [Year] } \\ \mathrm{NPV} & : \text { Net Present Value [Us\$] } \\ \mathrm{Pe} & : \text { Power [Kw Or Kwh } \\ \mathrm{Pr} & : \text { Profit [US\$] } \\ \mathrm{PV} & : \text { Present Value [US\$] } \\ \mathrm{PVF} & : \text { Present Value Factor [-] } \\ \mathrm{Q} & : \text { Heat [14] } \\ \mathrm{t} & : \text { Temperature [ }{ }^{\circ} \mathrm{c} \text { Or K] } \\ \eta & : \text { Efficiency [-] }\end{array}$

\section{Subscript}

$\begin{array}{lll}\text { AB.C } & : & \text { Absorption Chiller } \\ \text { conv } & : \text { Conventional System } \\ \text { ehr } & : \text { Exhaust Heat Recovery } \\ \text { eq } & : \text { Equipment, } \\ \text { h.storage } & : \text { Heat Storage } \\ \text { hm } & : \text { Heat Medium Of Absorption Chiller } \\ \text { ins } & : \text { Installation (Cost), } \\ \text { i.p.c } & : \text { Inlet Air Pre-Cooling } \\ \text { O\&M } & : \text { Operation And Maintenance } \\ \text { rep } & : \text { Replacement (Cost) } \\ \text { sal } & : \text { Salvage Value } \\ \text { SP@SR } & : \text { Single Payment Or Single Return }\end{array}$

\section{References}

1. Bruno, J.C., V. Ortega-López, and A. Coronas, Integration of absorption cooling systems into micro gas turbine trigeneration systems using biogas: Case study of a sewage treatment plant. Applied Energy, 2009. 86(6): p. 837-847.

2. Basrawi, M.F.B., et al., Analysis of the performances of biogas-fuelled micro gas turbine cogeneration systems (MGT-CGSs) in middle- and small-scale sewage treatment plants: Comparison of performances and optimization of MGTs with various electrical power outputs. Energy, 2012. 38(1): p. 291-304.

3. Basrawi, F., T. Yamada, and K. Nakanishi, Evaluation of the performance of a micro gas turbine cogeneration system in a sewage treatment facility: Optimized configuration of a cogeneration system. Heat Transfer-Asian Research, 2013. 42(6): p. 556-568.

4. Sugiartha, N., et al., Trigeneration in food retail: An energetic, economic and environmental evaluation for a supermarket application. Applied Thermal Engineering, 2009. 29(13): p. 2624-2632.

5. Moya, M., et al., Performance analysis of a trigeneration system based on a micro gas turbine and an air-cooled, indirect fired, ammonia-water absorption chiller. Applied Energy, 2011. 88(12): p. 4424-4440.

6. Ehyaei, M.A. and M.N. Bahadori, Selection of micro turbines to meet electrical and thermal energy needs of residential buildings in Iran. Energy and Buildings, 2007. 39(12): p. 12271234.

7. Ehyaei, M.A. and A. Mozafari, Energy, economic and environmental (3E) analysis of a micro gas turbine employed for on-site combined heat and power production. Energy and Buildings, 2010. 42(2): p. 259-264.

8. Huicochea, A., et al., Thermodynamic analysis of a trigeneration system consisting of a micro gas turbine and a double effect absorption chiller. Applied Thermal Engineering, 2011. 31(16): p. 3347-3353.

9. Basrawi, F., T. Yamada, and S.y. Obara, Theoretical analysis of performance of a micro gas turbine co/trigeneration system for residential buildings in a tropical region. Energy and Buildings, 2013. 67(0): p. 108-117.

10. Zain, Z.M., M.N. Taib, and S.M.S. Baki, Hot and humid climate: prospect for thermal comfort in residential building. Desalination, 2007. 209(1-3): p. 261-268.

11. Lau, K.Y., et al., Performance analysis of hybrid photovoltaic/diesel energy system under Malaysian conditions. Energy, 2010. 35(8): p. 3245-3255.

12. Basrawi, F., T. Yamada, and S.y. Obara, Economic and environmental based operation strategies of a hybrid photovoltaic-microgas turbine trigeneration system. Applied Energy, 2014. 121(0): p. 174-183.

13. Cooperation, C.T. Energy Effciency The Cool Way. 2015.

14. Cho, W. and K.-S. Lee, A simple sizing method for combined heat and power units. Energy, 2014. 65(0): p. 123-133. 